\title{
Reinterpreting the Life and Art of Grant Wood: A Review Essay
}

\author{
TRAVIS E. NYGARD
}

Grant Wood: A Life, by R. Tripp Evans. New York: Alfred A. Knopf, 2010. xii, 402 pp. Illustrations, notes, bibliography, index. \$37.50 cloth.

R. TRIPP EVANS'S new biography of Grant Wood is a provocative book about Iowa's most celebrated artist. As the most thorough examination of Grant Wood's psyche ever written, the book is intellectually engaging. It also embeds Wood's story in the history of gender and sexuality in America.

Evans's thesis is that Wood "attempted to present himself and his work as the reflection of 'authentic' American manhood - conceived as heterosexual, hardworking, wholesome, and patriotic - precisely because he believed he had fallen short of this model himself" (6). Readers are likely to disagree with specific points in Evans's analysis, but this is not a shortcoming. Indeed, asking readers to wrestle with new interpretations of material from the past is a hallmark of historical writing that is worth reading.

Evans is an eclectic scholar and a talented storyteller. He previously published a book on how ancient Mayan art was understood during the nineteenth century, recounting the often amusing histories of explorers and scholars. He now claims to be working on a history, spanning thousands of years, of a plot of land in Providence, Rhode Island, where he lives. Sandwiched

THE ANNALS OF IOWA 70 (Fall 2011). (C) The State Historical Society of Iowa, 2011. 
between these radically different intellectual projects is the biography of Grant Wood at hand. It is being marketed to a general audience. Evans uses accessible language and does not assume prior familiarity with scholarship on Wood. The book's production values are high, with many illustrations, including color plates. The index is done well and is easy to use. Scholarly citations and a bibliography are included at the back of the book.

A NEW BIOGRAPHY of Wood was overdue, and this book will no doubt remain a standard reference. Biography has been a time-honored way to approach art history, beginning with the first art history book - Giorgio Vasari's Lives of the Artists (1550). That said, as a biography Evans's book is nontraditional. Rather than framing Wood as an anomalous creative genius, he paints the artist as the product of specific training and circumstances. Rather than focusing on Wood's public façade, he emphasizes how he was a misfit who hid his opinions about the world.

What writing about Wood, then, does this book compete with for attention? The first major biography of Wood, written by the journalist Darrell Garwood, is 67 years old. Although it remains valuable, scholars today treat it cautiously. It was written in a frenzy during the two years following Wood's death in 1942, based on records of the artist's life and interviews with most of the people who knew him best. Despite such strong source material, Grant Wood's sister, Nan Wood Graham, considered the book a gossipy exercise that "wasn't fit to spit on" (quoted in Evans, 300). Nan, who understood herself to have been the guardian of Grant Wood's reputation, subsequently wrote her own biography, My Brother, Grant Wood, which is profoundly insightful, but also fragmented and biased. It is composed as a series of personal remembrances, and its tone is consistently celebratory. The last biography worthy of note is Grant Wood and Marvin Cone: Artists of an Era (1972), by Hazel Brown, a personal friend of the two artists named in the title. As could be expected, her book took the form of a tribute filled with anecdotes. ${ }^{1}$

1. Darrell Garwood, Artist in Iowa: A Life of Grant Wood (1944; reprint ed., Westport, CT, 1971); Nan Wood Graham, with John Zug and Julie Jensen McDonald, My Brother, Grant Wood (Iowa City, 1993); Hazel E. Brown, Grant Wood and Marvin Cone: Artists of an Era (Ames, 1972). 
Evans has provided a valuable service by synthesizing key facts of Wood's life recounted in these earlier biographies and presenting them in one volume. But his book does much more than simply repackage well-known information. This is the first book-length biography of Wood written by a scholar with critical distance from the artist. It is also the first biography published since Nan's death in 1990. Thus, Evans clearly felt more free to speak openly about Wood's shortcomings and life challenges than earlier authors.

DEFINITIVE HISTORICAL STUDIES are, by necessity, built through the drudgery of archival research, and Evans did his fair share. It is particularly notable that he was able to exploit the previously unknown papers of Sara McClain Sherman Grant Wood's wife from 1935 to 1939 - including her unpublished memoirs. He revisited materials on Grant Wood in the Smithsonian Institution's Archives of American Art - most importantly a set of scrapbooks that were compiled by Nan as well as information in the collections of the State Historical Society of Iowa. He also conducted interviews and corresponded with individuals who had valuable insights. These efforts significantly enhance his book.

In terms of reliability, Evans has accurately recounted the unambiguous facts of Grant Wood's life story. I have read the scholarship on Wood and used many of the archives that Evans relied on. My own research on Wood - a doctoral dissertation - was not biographical; instead it framed several of Wood's works of art within the broader story of American farming. ${ }^{2}$ Although I had different questions in mind when researching Wood than Evans did, I would have noticed glaring historical errors if they were present.

This book is sure to be contentious, however, because of its analysis. Rather than perceiving Grant Wood as an open book, Evans believes that the artist obscured his core identity. In particular, Evans asserts that Wood hid ambivalent feelings toward

2. Travis Earl Nygard, "Seeds of Agribusiness: Grant Wood and the Visual Culture of Grain Farming, 1862-1957" (Ph.D. diss., University of Pittsburgh, 2009), available online at http://etd.library.pitt.edu/ETD/available/etd$12102009-160845 /$. 
his father and the fact that he himself was gay. To recover a more complete understanding of Wood, Evans combed textual material for clues about his mindset. He also interprets Wood's art as a window into his subconscious. He makes use of some psychoanalytic theory - especially ideas developed by Sigmund Freud - but the narrative remains mostly free of psychological jargon.

Using psychoanalysis to access the minds of long-dead people is a questionable methodology, as it is difficult to test assertions made thereby. Psychoanalytic interpretation is, however, respected by some who work in the humanities. In the case of art history, it began with Freud himself, who wrote an essay about Leonardo da Vinci. ${ }^{3}$ In the case of Grant Wood, the scholar Sue Taylor has explored his psyche in award-winning work. ${ }^{4}$ Do such psychoanalytic interpretations, in Evans's words, go "too far - destroying the innocence of the artist's intentions?" He says no, emphasizing that it is important to pay attention to "the psyche's raw and anarchic operations" (277). But what do these operations consist of?

When discussing hidden and subconscious aspects of Grant Wood's life and work, Evans's prose becomes titillating. Because Wood made art that is overtly straitlaced, readers will be surprised to encounter words such as "penetrative gaze," "cock ring," "seminal release," "incestuous relationship," "phallic shape," and "castration" (115, 119, 253, 278, 281). Such carnal language is jarring, and I suspect that Evans was cunning in his choice to use it. He wants us to abandon any preconceived notions we may have of Wood as a sexless one-dimensional bumpkin. To place such language in context, an example of one of Evans's new interpretations is in order.

During the process of writing this review essay I showed Grant Wood's art to a friend of mine who is an art therapist, Jacqueline Lindo. She has a special interest in serving lesbian, gay, bisexual, and transgendered people, and she has become a prominent leader of the queer community in Milwaukee. We

3. Sigmund Freud, Leonardo da Vinci and a Memory of His Childhood (1910; reprint ed., New York, 1990).

4. Sue Taylor, "Grant Wood's Family Album," American Art 19 (2005), 48-67; idem, "Wood's American Logic," Art in America 94 (2006), 86-93. 
discussed Evans's interpretations of several landscapes, including Stone City (1930). Evans explains how Stone City came into being as an image that overtly celebrates a location in rural Iowa to which Wood had some sentimental attachment. Evans then reveals that the image also may contain overtones of sex acts.

Although Wood may have disguised the sexual nature of his landscapes, even to a certain degree from himself, the object of his desire is only partially abstracted in these works - for in the undeniably erotic curves of Stone City, we register the muscular outlines of a powerful male body. The artist's autobiography routinely describes Iowan scenery in stereotypically male terms. The land is raw, solid, thrusting, and active; through its 'rounded, massive contours, [it] asserts itself through everything that is laid upon it.' Stone City similarly suggests the land's virility and sexual potency. From his broadly stroked sketch to the work's final, polished execution, the artist transforms his composition into the rigid smoothness of an erect penis - and even includes, in the work's foreground, a seemingly endless battalion of ejaculatory corn sprouts (134).

Most surprisingly, Evans detects an interest in anal eroticism in the image.

Not only does Wood reveal his reverence for the male body in Stone City, but he also suggests its potential for penetration. In the curiously clefted hill that appears in the painting's upper-righthand corner, the viewer registers a pair of rounded, passively upturned buttocks. Firmly belted by an encircling road, they are penetrated at their base by a felicitously placed tree (135).

Lindo and I were fascinated by Evans's ideas. Ultimately, however, we decided to be cautious about endorsing his highly specific, sexual, and masculine reading of the land. We agreed that his paintings of rolling hills are appealing, in part, because the curves evoke bodies. We were unable, however, to agree about specifics of anatomy or gender.

Evans acknowledges his potential for fallibility, noting that "not only will we never know the full extent of the artist's unconscious motivations, but as author and reader we inevitably bring our own psychological histories and perspectives to these images" (277-78). Given the ambiguity that we found in the images, it is probable that Evans has projected some of his own 
mindset onto them. Regardless of whether that is the case, such radical new interpretations have value, in that they force us to ponder what may be present in the images that is not immediately apparent.

For readings of Wood's art that focus on overt rather than subconscious content, I recommend referring to several previously published books. Monographs by Wanda Corn, James Dennis, John Zug, Brady Roberts, James Horns, and Helen Parkin remain valuable. These authors carefully contextualize the imagery at its moment of creation. The total message of each work of art is emphasized, as supported by visual details. Similarly, for treatment of Wood's decorative arts, the catalog assembled by Jane Milosch with the assistance of Wanda Corn, James Dennis, Joni Kinsey, and Deba Foxley Leach is the standard reference. For discussions of murals and drawings, one should refer to the work of Lea Rosson Delong, who worked with Henry Adams, Sally Parry, Kent Ryden, Warren Madden, Olivia Madison, Lynette Pohlman, and Wendy Wintersteen to produce a definitive study. Lastly, for treatments of Wood's most iconic painting, American Gothic, books by Steven Biel and Thomas Hoving are filled with rich commentary. ${ }^{5}$

OVER THE COURSE of Evans's biography, readers will come to see Wood as an eccentric individual, unafraid to break social norms, who savored physical pleasures. We learn of his love of being nude outdoors - skinny-dipping throughout his life. As a young man, he would shed his clothes during summer thunderstorms to enjoy the sensations of water gliding across his body - a practice he called "shower baths" (33). He also loved

5. Wanda M. Corn, Grant Wood: The Regionalist Vision (New Haven, CT, 1983); James Dennis, Grant Wood: A Study in American Art and Culture (New York, 1975); John Zug, ed., This Is Grant Wood Country (Davenport, 1977); Brady Roberts et al., Grant Wood: An American Master Revealed (San Francisco, 1995); Jane C. Milosch, ed., Grant Wood's Studio: Birthplace of American Gothic (Cedar Rapids and New York, 2005); Lea Rosson DeLong, Grant Wood's Main Street: Art, Literature and the American Midwest (Ames, 2004); idem, When Tillage Begins, Other Arts Follow: Grant Wood and Christian Petersen Murals (Ames, 2006); Steven Biel, American Gothic: A Life of America's Most Famous Painting (New York, 2005); Thomas Hoving, American Gothic: The Biography of Grant Wood's American Masterpiece (New York, 2005). 
the intoxicating effects of alcohol. We learn of shocking levels of excess consumption, such as drinking two bottles of scotch per day. Despite a willingness to deviate from convention and live in the spotlight, there is one aspect of Wood's life that he kept private - his sexuality.

Evans adamantly wants us to see Wood as a closeted gay man with a robust libido. Such framing provides narrative and analytical continuity in the biography. It is also in accordance with the general consensus emerging among art historians working on Grant Wood, including me, that he probably had some level of erotic interest in men. ${ }^{6}$ The most compelling evidence in regard to Wood's sexuality is visual. Making generalizations about Wood's body of work is dangerous, given that no one has ever compiled a catalogue raisonné. Extrapolating from the major monographs, however, it is clear that he rendered at least seven images of the male nude in his lifetime. Those nudes ranged from academic to sensuous to humorous. It is a short jump from this observation to concluding that Wood was sexually interested in male bodies - especially given that he seems never to have created any female nudes at all.

Evans merits praise for writing a gay and lesbian history that takes place in rural Iowa before the sexual revolution of the 1960s. To the best of my knowledge, this is the first book-length study to take on such a topic, and it was no doubt challenging to complete. There is some scholarship on minority sexual iden-

6. Works that discuss Wood's sexuality include John E. Seery, "Grant Wood's Political Gothic," Theory E Event 2 (1998), pars. 1-23; Taylor, "Wood's American Logic," 86-93; idem, "Grant Wood's Family Album," 48-67; James H. Maroney Jr., Hiding in Plain Sight: Decoding the Homoerotic and Misogynistic Imagery of Grant Wood (Leicester, VT, 2006; self-published book, available online at http://jamesmaroney.com/Art/Grant_Wood/Hiding_in_Plain_Sight_full.pdf); Jonathan Weinberg, Male Desire: The Homoerotic in American Art (New York, 2005), 76-77; Biel, American Gothic, 25, 53; Hoving, American Gothic, 122; Robert Hughes, American Visions: The Epic History of Art in America (New York, 1997), 194; Dennis Domer, "Homeplace in Life and Art," in Remembering the Family Farm: 150 Years of American Prints, ed. Stephen H. Goddard (Lawrence, KS, 2001), 17; Nygard, "Seeds of Agribusiness," 268-69; Jonathan Katz and David C. Ward, "Arnold Comes of Age," in Hide/Seek: Difference and Desire in American Portraiture (Washington, DC, 2010), 112-13. Henry Adams began scholarly debates about Wood's sexuality in a presentation titled "The Truth about Grant Wood," given at the College Art Association conference on February 24, 2000. 
tity in the broader region. ${ }^{7}$ Needless to say, however, more research remains to be done. Indeed, because of the existence of anti-sodomy laws and social stigma, much of the subculture would have been clandestine.

The examples Evans uses to enrich our understanding of this subculture extend beyond Wood. We learn of a lesbian couple in Cedar Rapids, one of whom (Frances Prescott) was a school principal where Wood worked and the other (Dr. Florence Johnston) was a medical anesthesiologist. We learn that Wood organized a summer art school in Stone City, along with the openly gay artist Adrian Dornbush. We see how Wood's colleague and friend, the artist Thomas Hart Benton, perceived the artist community as being filled with gay men. We even learn how gay men gathered to socialize in houses such as Wood's before the widespread establishment of businesses catering to the queer community. With this culture reconstructed, we can imagine that Wood had a life within it that was personally satisfying.

In some ways Grant Wood makes a great hero for gay people of the twenty-first century. He resisted the social pressure to establish a traditional heterosexual nuclear family with children, instead embracing a broader network of relatives, friends, and colleagues for companionship and support.

It is important to note, however, that specifics about Grant Wood's sexuality are elusive. If Wood was sexually active with other men, then he obscured the fact well. No one has ever firmly identified a man with whom Wood was romantically involved or having sex. The only man that Evans pinpoints as having been perceived to be a lover of the artist is Park Rinard Wood's personal secretary. On this topic, Evans builds on an analysis by Joni Kinsey. According to minutes of a meeting at the University of Iowa, Wood's colleagues thought that his arrangement with Rinard was "strange." ${ }^{8}$ Unfortunately, the document does not indicate the nature of this strangeness, leaving our imaginations free to ponder the innumerable possibilities - sexual, financial, intellectual, professional, and so forth.

7. See, for example, Will Fellows, Farm Boys: Lives of Gay Men from the Rural Midwest (Madison, WI, 1996).

8. Joni Kinsey, "Cultivating Iowa: An Introduction to Grant Wood," in Milosch, ed., Grant Wood's Studio, 284. 
A reporter from Time Magazine nearly reported on the incident, intending to frame it as a homosexual scandal. Was there truth in the allegation? Evans ultimately concludes that it is unlikely that Wood and Rinard were romantically involved because Rinard was a heterosexual man.

What is clear is that some of Wood's colleagues at the University of Iowa perceived him to be gay, and innuendo suggests that his wife and others did too. The most direct written evidence of Wood's homosexuality is the testimony of his former wife, Sara Sherman. Although she did not comment on Wood's sexual orientation directly, in her unpublished biography she noted that he suffered from a "war within the individual" comparable to that of Oscar Wilde's (quoted in Evans, 308). It was common knowledge that Wilde, a nineteenth-century author, was publicly prosecuted for sodomy. As such, the comparison is telling.

Given that direct testimony about Wood's bedroom romps is thin, it will remain possible to see Wood's sexuality in many ways. Evans mentions dissenting perspectives on the issue, although these are only glibly analyzed. Readers can thus choose whether to wholeheartedly accept Evans's claim that Wood was gay or to focus on ambiguous evidence.

One possibility is that Wood may have had satisfying erotic relationships with women. Even if he ultimately identified as a gay man, Wood could have experienced transient bisexual yearnings throughout life. Evans acknowledges that Nan tells several stories about Grant Wood's dating of women in her book My Brother, Grant Wood, but Evans considers her to be either mistaken or lying. To the best of my knowledge, no one who knew Nan personally ever accused her of spinning yarns about the artist's relationships with women, so it is possible to take her claims at face value. She tells us that Wood canoodled with an American expatriate woman named Margaret in Parisian cafés, that he nearly fell for another woman in Iowa, and that his marriage to Sara Sherman would have been happy if it were not for struggles over money. In light of Wood's willingness to marry Sherman, it is probable that he explored the possibility of other relationships with women.

It is also possible that Wood had a low sex drive or was fully asexual - another interpretation that Evans gives a nod to. In 
his autobiography, the heterosexual novelist MacKinlay Kantor recounted an in-depth conversation with Wood about his erotic consciousness - the only such conversation on record - that took place during heavy drinking that lasted all night. ${ }^{9}$ Kantor claimed that Wood explained "how the whole sexual problem was a closed book to him, and why." Kantor further explained that "people who did not know [Wood] well, and read about him or met him casually ... whispered that he was a homosexual." Kantor viewed these rumors as erroneous, claiming that Wood was "nothing of the kind. He was simply asexual" (quoted in Evans, 284-85). A glance at photos of Wood reveals that he was a slightly overweight person who retained his baby fat - features typical of male bodies without much testosterone, such as eunuchs. I can therefore imagine that the artist's libido was weak. Ultimately, the question of whether Wood can best be understood as gay, straight, bisexual, asexual, or something else entirely will remain open for debate.

TAKING EVANS'S BIOGRAPHY as a whole, we might ask if this is the last word on Grant Wood. I don't think so. The many new interpretations of art, new facts discovered, and new questions raised will engender new debates about the artist in the coming years. Evans's book will likely become a definitive reference for questions about Wood's gendered and sexual identity, but many topics remain to be fleshed out by others. I, for one, would like to see scholars further interrogate Wood's politics, religion, and finances. I thus look forward to reading the next batch of books and articles about one of the twentieth century's most intriguing artists.

R. Tripp Evans won the State Historical Society of Iowa's Benjamin F. Shambaugh Award, recognizing Grant Wood: A Life as the most significant book on Iowa history published in 2010.

8. MacKinlay Kantor, I Love You, Irene (Garden City, NY, 1972). 